\title{
Intrinsic Motivation, Job Autonomy and Turnover Intention in the Italian Healthcare: The Mediating Role of Affective Commitment
}

Maura Galletta (Corresponding author)

Department of Psychology, University of Cagliari

Via Is Mirrionis 1, 09123 Cagliari, Italy

Tel: 39-070-675-7515 E-mail: maura.galletta@gmail.com

Igor Portoghese

Department of Psychology, University of Cagliari

Via Is Mirrionis 1, 09123 Cagliari, Italy

Tel: 39-070-675-7515 E-mail: igor.portoghese@gmail.com

Adalgisa Battistelli

Laboratory Epsylon Dynamics of Human Abilities and Health Behaviors, Université Paul Valéry Montpellier 3

4 Boulevard Henri IV, 34000 Montpellier, France

Tel: 33-4-6760-1193Ｅ-mail: adalgisa.battistelli@univ-montp3.fr

Received: March 25, 2011 Accepted: April 19, 2011 doi:10.5296/jmr.v3i2.619

\begin{abstract}
Drawing on Self-Determination and Work Characteristics theories, we hypothesized that job autonomy and intrinsic motivation were key exogenous variables positively related to affective commitment, which in turn is negatively related to turnover intention, by performing a mediating role. A sample of 442 nurses has been involved in this research. Through the cross-validation technique, the results showed that the hypotheses of this study were supported and affective commitment completely mediated the relationships between job autonomy, intrinsic work motivation and turnover intention. These findings have important
\end{abstract}


implications for healthcare organizations by helping to promote effective work environments and major opportunities of responsibility to workers to develop their own activity. Conclusions were examined considering practical implications for organizations, employees and the need for further researches.

Keywords: Work motivation, Job autonomy, Affective organizational commitment, Turnover intention, Italian healthcare 


\section{Introduction}

Employee voluntary turnover is a persistent phenomenon that produces a serious problem for organizations. The loss of qualified and skilled employees is related to the reduction in the competitiveness, innovation, and quality of offered service to patients (Miller, 2010). Moreover, turnover entails significant costs of recruitment, selection, hiring and training of newcomers (Abbasi \& Hollman, 2008).

In the healthcare field, nursing turnover is a widespread problem in the vast majority of post-industrialized countries. Actually, in Italy, a worrisome shortage of nursing has been observed, and the Italian Federation of Nurses has estimated a current shortage of 40000 nurses (Destrebecq, Terzoni, Colosso, Neri, \& Brambilla, 2009). Wagner (2010) asserted that nursing turnover is a dangerous outcome because it is linked to loss of individual and organizational performance, significant reduction in quality of care, increase in workload on the staff that survived the turnover, loss in morale, and further turnover. Excessive turnover can determine the so-called "dysfunction" in organizations. In fact, recent studies showed that a high nursing turnover can impact negatively on the organization's ability to efficiently respond to the needs of patients, and to provide them a high level of care (Tai, Bame \& Robinson, 1998; Shields \& Ward, 2001).

Several researches have been conducted to study factors related to turnover behavior of workforce, by proposing and testing a variety of turnover process models (Griffeth, Hom \& Gaertner, 2000; Hom \& Griffeth, 1995; Richer, Blanchard \& Vallerand, 2002). Particularly, researchers evidenced that intention to leave is one of the most important and accurate predictors of actual turnover (Kash, Naufal, Cortés, \& Johnson, 2010; Takase, Yamashita, \& Oba, 2007; Waters \& Roach, 2006). This is because, according to the theory of planned behavior (Ajzen, 1991), individual intentions or plans are the best predictors of behavior. For this reason, our study has considered turnover intention as an outcome variable.

Many researchers have tried to understand the major determinants of turnover intention with the purpose of providing some managerial implications (Tuzun, 2007). Studies have shown that organizational commitment is one of the most important predictors of intention to leave: mainly, in cases where the strength of bond with organization results from emotional identification with it (Meyer, Becker \& Vandenberghe, 2004). This relationship has been well documented in previous researches (e.g., Carmeli \& Gefen, 2005), but relatively few studies have focused on the motivational factors underlying turnover intention, such as job autonomy and work motivation (Richer et al., 2002), and how these variables are related to affective commitment. In fact, self-determination theory (SDT) (Deci \& Ryan, 1985; Gagné \& Deci, 2005) asserts that autonomous forms of motivation are the result of psychological needs satisfaction, and autonomy is one of the most important needs. Furthermore, self-determination is associated with increased psychological functioning (Deci, 1980), so that autonomous motivation should lead to positive outcomes.

Thus, the purpose of our study is to analyze how job autonomy and intrinsic work motivation play a fundamental role in the relationship with affective commitment, and how it mediates their effects on turnover intention. 


\section{Literature Review, Theoretical Model and Hypotheses Development}

\subsection{Relationship between Job Autonomy, Intrinsic Motivation and Affective Commitment}

According to the SDT, the extent to which work environment sustains and promotes the job autonomy of employees, allows them to activate positive and autonomous work behaviors. This condition is considered as a fundamental factor which is capable of promoting employees' work motivation, well-being and satisfaction (Camerino \& Mansano Sarquis, 2010; Camerino, Conway, \& Lusignani, 2005). In line with such findings, a meta-analysis conducted by Humphrey, Nahrgang, and Morgeson (2007) showed that perceived job autonomy is positively related to important work outcomes, such as performance, job satisfaction, organizational commitment, and intrinsic motivation. Gagné and Deci (2005) stated that the need for autonomy is fundamental to the emergence of intrinsic motivation that is the motivation to perform an activity for itself driven by pure interest and the pleasure of acting (Deci, Connell, \& Ryan, 1989).

The Job Characteristics Model (JCM; Hackman \& Oldham, 1976) suggested that job autonomy is the extent to which a job allows freedom, discretion and independence to schedule work, make decisions, and choose the procedures and methods to perform activities (Morgeson \& Humphrey, 2006). With a highly independent job, employees can perceive work outcomes as mostly depending on their efforts, feeling personally responsible for the success or failure of the actions. Therefore, among job characteristics, job autonomy could activate critical psychological states that facilitate several positive employee states like intrinsic motivation (Pierce, Jussila, \& Cummings, 2009). Richer et al. (2002) in their longitudinal study showed that job characteristics positively influenced self-determined motivation, even though it is not clear how each dimension is specifically related to work motivation.

Yet, job autonomy is capable of stimulating high levels of commitment to organization (Parker, Wall \& Cordery, 2001), specifically affective commitment regarding the employee's willingness to maintain the membership to organization and work to help out to accomplish its goal (Meyer \& Allen, 1991; Mowday, Steers \& Porter, 1979). To support these considerations in the nursing field, results from the study of Kramer and Schmalenberg (2002) concerning the traits/characteristics capable of creating attractive working environments for nurses, showed that autonomy and responsibility level perceived by workers during their daily practice, is among the most important factors related to retention strategies. Driven by these findings, controlling own work through autonomy, could increase intrinsic motivation and affective commitment.

Hypothesis 1: Job autonomy is positively related to intrinsic motivation.

Hypothesis 2: Job autonomy is positively related to affective commitment.

\subsection{Relationship between Intrinsic Work Motivation and Affective Commitment}

Even though theories of motivation and commitment are associated with different historical traditions, similarities between the two concepts have been recently highlighted by Meyer 
and colleagues (2004): both are energizing forces with implications for the behavior. In fact, Pinder (1998), defined motivation as a body of energizing forces, while Meyer and Herscovitch (2001) defined commitment as a force connecting the individual to a course of action. Meyer et al. (2004) in accordance with Becker, Billings, Eveleth, and Gilbert (1996), indicated that "the primary bases for the development of affective commitment are personal involvement, identification with the relevant target, and value congruence" (p. 994). These factors seem to be supported by intrinsic or autonomous motivation, and they contribute to the likelihood that an individual will become involved in a course of action. Despite the lack of sufficient studies in literature on the causal relation between motivation and commitment, these observations entail that motivation could be one of the primary bases through which commitment develops. In order to support this assertion about the relationship between motivation and commitment, Bono and Judge (2003) highlighted a positive relationship between autonomous motives for accomplishing work objectives and affective commitment. Moreover, Lam and Gurland (2008) found that self-determined work motivation predicted identification commitment. Finally, Millette and Gagné (2008) showed that autonomous motivation of volunteer workers was positively related with their engagement in the volunteer work.

Based on these results, it will be likely that when people feel to have to accomplish work tasks, they will become attached to, and feel obliged toward their own organization.

Hypothesis 3: Intrinsic motivation is positively related to affective commitment.

\subsection{The Mediating Role of Affective Commitment between both Job Autonomy and Intrinsic Motivation and Turnover Intention}

Commitment is considered as a fundamental factor for the development of the individual-organization relationship. Studies have shown that an emotionally involved employee is more satisfied (Khowaja, Merchand \& Hirani, 2005) and less inclined to leave the organization (Richer et al., 2002; Sjoberg \& Sverke, 2000), his/her performance is above average, he/she is motivated to propose work improvements and give a high value to his/her work. In fact, employees with high affective commitment have high emotional attachment, identification and involvement with the organizational goals. For this reason, they desire to remain as part of the organization (Gaan, 2008; Meyer, Allen, \& Smith, 1993; Thompson \& Prottas, 2005) and are not likely to leave (Meyer \& Allen, 1997). Empirical results showed that affective commitment was negatively related to intention to turnover (e.g., Allen \& Meyer, 1996; Clugston, Howell, \& Dorfman, 2000; Griffeth et al., 2000; Khatri, Budhwar, \& Fern, 2001), and particularly, Gautam, Dick and Wagner (2001) found that affective commitment is the only significant predictor of both search intentions and turnover intentions when compared to both continuance commitment and normative commitment.

Hypothesis 4a: Affective commitment is negatively related to turnover intention.

A recent study of Thatcher, Liu, Stepina, Goodman, and Treadway (2006) found that commitment mediated the influence of intrinsic work motivation on turnover intention. Moreover, although there are few researches that have analyzed the indirect impact of 
motivation on turnover intention (e.g., Richer et al., 2002), a recent study showed a negative direct relationship between motivation at work and turnover intention (Dysvik \& Kuvaas, 2010). Based on these findings, we hypothesize that intrinsic motivation will have an indirect impact on turnover intention via affective commitment.

Hypothesis 4b: Affective commitment mediates the relationship between intrinsic motivation and turnover intention.

Although there is no empirical evidence to support the indirect effect of job autonomy on turnover intention through the mediation of affective commitment, recently researchers showed that job autonomy is positively related to affective commitment (Karim, 2010; Parker, 2001) and has a negative relationship with turnover intention (Kim \& Stoner, 2008).

Thus, employees who have autonomy and freedom about how and when to do work, could feel a sense of responsibility for their tasks and activities. This would activate a sense of attachment to management and to one's own work environment that in turn could reduce employee's desire to leave the organization.

Hypothesis 4c: Affective commitment mediates the relationship between job autonomy and turnover intention.

\section{Method}

\subsection{Sample and Data Collection}

A cross-sectional survey design was performed. A sample of Registered Nurses was recruited for this study. This research involved 525 nurses from one hospital in the Italian Public Healthcare. Among these, 442 have been considered useful yielding a response rate of $84.2 \%$. Data were collected using a paper questionnaire. Questionnaires were distributed to nurses through the nurse supervisor of each unit. Participants voluntarily completed the questionnaire during working hours.

Results showed that most of the sample was women (79.7\%). The average age of women is $35.9(S D=7.24)$, men's is $35.4(S D=9.22)$ (range 23-60 years). Mean experience levels were 11.9 years $(S D=7.99)$ in the profession (range $1-34$ years) and 6.7 years $(S D=5.76)$ in unit (range 1-32 years).

\subsection{Measures}

Questionnaire included a part concerning personal data (gender, age, tenure, etc.) and another part regarding the measure scale of variables used in this study. Since the scales we used had not previously been validated in Italian, we used the translation-back translation procedure described by Brislin (1980). All items were rated on a five-point scale ranging from 1 (strongly disagree) to 5 (strongly agree).

Affective commitment. It was measured using three high-loading items (loadings from .64 to .81) from the Survey of Organizational Commitment (Meyer, Allen \& Smith, 1993). Sample items included "I do not feel "emotionally attached" to this department". 
Intrinsic work motivation. The Motivation at Work Scale (MAWS) from Gagné, Forest, Gilbert, Aubé, Morin, and Malorni, (2010) was used. Four high-loading items (loadings from .64 to .83) were selected. Sample items included "Because I enjoy this work very much".

Job autonomy. We used seven high-loading items (loadings from .75 to .83) from the Work Design Questionnaire (WDQ) (Morgeson \& Humphrey, 2006). Sample items included "The job allows me to plan how I do my work".

Turnover intention. Two items from Hom, Griffeth, and Sellaro (1984) were used. Sample items include "I am going to seek a job in another hospital next year", and "I intend to leave my unit to work in another unit in the same hospital next year".

\subsection{Ethical Consideration}

Approval to conduct the study in each hospital was obtained from the appropriate ethics committees. Participants were informed that their anonymity was granted. Informed consent to participate was assumed when nurses returned completed questionnaires.

\subsection{Data Analysis}

We used the two-step approach suggested by Anderson and Gerbing (1988). First, we examined the factorial structure of our measures through CFA. Moreover, since we used perceptual data for both independent and dependent variables in this study may raise concerns about common method variance. We examined this issue following Podsakoff, MacKenzie, Lee and Podsakoff's (2003) recommendation. In a second step, we examined the hypothesized relationships among variables, and tested alternative models.

In order to test the models, we used SEM via AMOS 7.0 (Arbuckle, 2006) with maximum likelihood. We used the following fit indices: the Tucker-Lewis Index (TLI), the Comparative Fit Index (CFI) and the Root-Mean-Square Error of Approximation (RMSEA). Hu and Bentler (1999) suggest that to reduce errors of I and II type, the best combination of fit indices should have a RMSEA cutoff value $\leq$ of .06 and a TLI and CFI value $\geq$ of .95. Finally, we used Akaike's information criteria (AIC: Akaike, 1987) to compare two or more models. The hypothesized model with the lowest level is the one with the best fit ( $\mathrm{Hu} \&$ Bentler, 1995).

Given a good sample size, we carried out the cross-validation technique of models (Bergman, Langhout, Palmieri, Cortina, \& Fitzgerald, 2002). We split overall sample into two random parts. A first random half sample (training sample, $n=213$ ) has been used to verify scales' structure, the common method variance issue, hypothesized model and alternative models 1 and 2; the other half sample (validation sample, $n=229$ ) has been used to cross-validate the obtained results regarding common method variance, alternative model 3 , and mediation effect analyses.

Regarding the mediation analyses, we used the bootstrap method to determine the confidence intervals for mediation effects. Confidence intervals provide a range of plausible population values for the mediation effect (MacKinnon, Lockwood, \& Williams, 2004; Preacher \& 
Hayes, 2008). Through the computation of bootstrapped confidence intervals (CIs), it is possible to avoid some problems due to asymmetric and other non-normal sampling distributions of an indirect effect (MacKinnon et al., 2004). As Cheung and Lau (2008) recommended, confidence intervals were constructed from 1000 bootstrap samples. A resulting model of variables related to turnover intention was developed.

Table 1 shows descriptive statistics and correlations among variables analyzed in this study. They are all significantly correlated. The magnitude and direction of these correlations are consistent with predictions.

Table 1. Means, standard deviation and correlations among variables of study

\begin{tabular}{llcccccc}
\hline \multicolumn{1}{c}{ Variable } & $M$ & $S D$ & 1 & 2 & 3 & 4 \\
\hline 1. & Job autonomy & 2.96 & .79 & $(.94)$ & & & \\
2. & Intrinsic work motivation & 3.56 & .81 & $.46^{*}$ & $(.84)$ & & \\
3. & Affective commitment & 3.36 & .92 & $.50^{*}$ & $.51^{*}$ & $(.85)$ & \\
4. & Turnover intention & 1.83 & .98 & $-.14^{*}$ & $-.14^{*}$ & $-.35^{*}$ & $(.87)$ \\
\hline
\end{tabular}

$\mathrm{N}=442$. Cronbach's Alpha is shown in parentheses. ${ }^{*} \mathrm{p}<.01$ (2-tailed)

\section{Results}

\subsection{Exploratory and Confirmatory Factor Analysis}

For the best fitting measurement and structural model, we tested the discriminant validity of the constructs via Exploratory Factor Analysis (EFA) with Maximum Likelihood extraction method. Results showed 4 factors with Eigenvalues over 1, explaining about $65 \%$ of the variance of the indicators. The KMO (Keiser Meyer Olkin) measure of sampling adequacy was .880 and the Bartlett's Test of Sphericity was significant $\left(\chi^{2}(d f=120)=2049.46, p\right.$ $<.001$ ), indicating adequate inter-correlations among the indicators and the suitability of the factor analysis (Hair, Black, Babin, Anderson, \& Tatham, 2006).

CFA to confirm goodness of the measurement model for both the exogenous and endogenous variables was conducted. We did not need for item parcel because we have subsamples with high observations to variables set ratio over the 10:1 (Nunnally, 1978). All items loaded significantly onto their own latent factor ( $p<.001$, ranging from .54 to .89). The four-factor model was supported, and showed a good fit to the data (see Table 2). Overall, there were 4 latent constructs and 16 manifest variables.

\subsection{Common Method Variance Issue}

When dependent and independent variable data are entirely self-reported, common method bias can be a potential problem. Following Podsakoff et al.'s (2003) recommendation, a test for common method bias was conducted on our data using the unmeasured latent method factor. This procedure separates response variance into three components: trait, method, and random error. As Richardson, Simmering and Sturman (2009) argued, the first estimated model, the trait-only model, is a measurement model of a given independent-dependent construct pair that includes a null method construct. That is, the method construct is specified 
to be uncorrelated with the independent and dependent constructs and no path to or from the method construct is estimated. In the second or method-only model, the independent and dependent constructs are null, but the paths from the method construct to all manifest indicators of the independent and dependent constructs are estimated. The third, or trait/method model, is identical to the trait-only model, but paths from the method construct to all the independent and dependent construct manifest indicators are added. Finally, the trait/method-R model is identical to the trait/method model, but the independent-dependent construct correlation is constrained to the value obtained from the trait-only model. If the trait-only model fits the data better than the method-only model, there is evidence that observed variance in the independent and dependent constructs is not due to the method alone. If the trait/method model fits better than the trait-only model, there is evidence that trait-based and method variance are present in the data. If the trait/method-R model fits significantly worse than the trait/method model, there is evidence of bias because of common method variance.

Comparing $\chi^{2}$ values for the "Trait/Method" and "Trait/Method-R" models, as recommended by Richardson et al. (2009), there was no evidence of a significant worsening of model fit indices: $\Delta \chi_{(16.92)}^{2}(\Delta d f=9)=2.7, p>.05$. We found that all significant relationships held after controlling for the latent common method variance factor, providing evidence that common method variance is not an issue in this first half sample.

To further address any worries due to common method variance, results of the training sample were cross-validated using the validation sample. Again, there was no evidence of a significant worsening of model fit indices: $\Delta \chi_{(16.92)}^{2}(\Delta d f=9)=5.1, p>.05$. These results evidenced that common method variance is not an issue in this study. The results are shown in Table 3.

\subsection{Structural Equations Modeling Analyses}

We tested our model via structural equations modeling analyses. The hypothesized model showed a good fit to the data, $\chi^{2}(97, n=213)=154.3, p<.001$, CFI $=.97$, TLI $=.96$, RMSEA $=.05$. All factor loadings were significant. A look at path coefficients reveals that all paths were significant $(p<.05)$. Results showed a positive relationship between job autonomy and intrinsic motivation $(\beta=.53, p<.001)$, supporting the Hypothesis 1 . In accordance with Hypotheses 2 and 3, job autonomy and Intrinsic motivation were significantly related to affective commitment $(\beta=.33, p<.001 ; \beta=.38, p<.001$, respectively) which in turn is negatively related to turnover intention $(\beta=-.46, p<.05)$. This result supported the hypothesis $4 \mathrm{a}$. The model explained $28 \%$ of the variance of intrinsic motivation, $39 \%$ of the variance of affective commitment and $21 \%$ of turnover intention. Standardized coefficients for the hypothesized model are presented in Figure 1. 


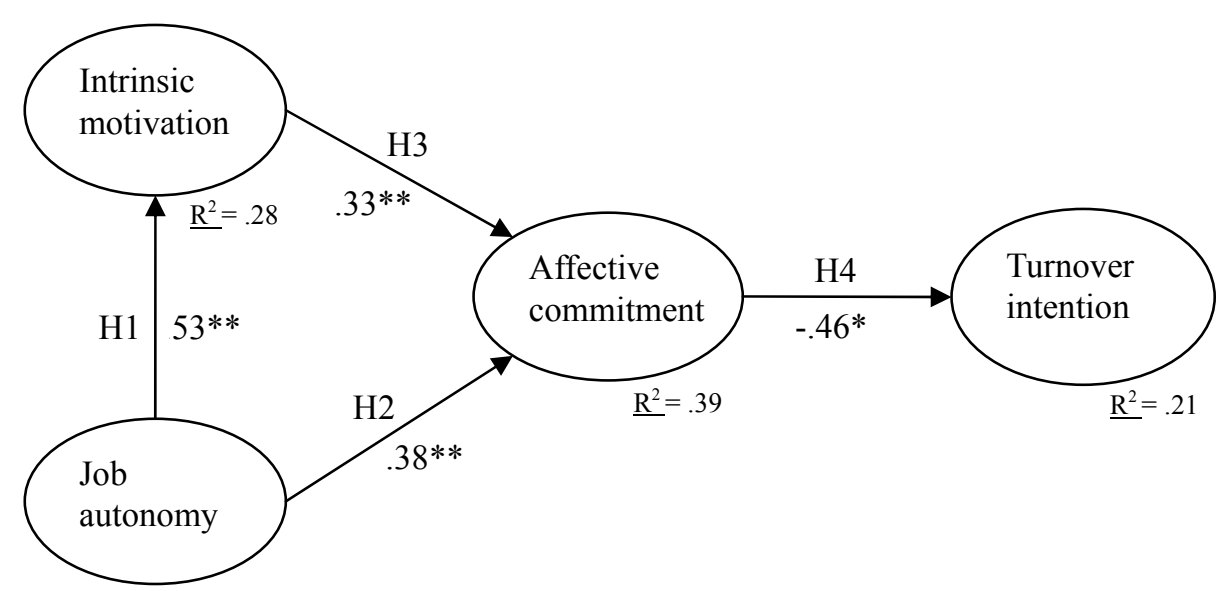

Figure 1. Hypothesized model with standardized path coefficients on training sample.

$$
n=213 .{ }^{*} p<.05, * * p<.001 \text {. }
$$

\subsection{Alternative Models}

To determine whether our model was parsimonious, and to examine assumptions about hypothesized mediations, we compared our hypothesized model to three alternative models. Model 1 added a path from intrinsic motivation to turnover intention, $\Delta \chi_{(3.84)}^{2}(\Delta d f=1)=1.3$, $p>.05$; Model 2 added a path from job autonomy to turnover intention $\Delta \chi_{(3.84)}^{2}(\Delta d f=1)=$ $1.7, p>.05$. These added paths were supported by the correlation analysis which showed a significant correlation between these variables. If fit indices improve significantly with the inclusion of these direct paths, partial mediation would be supported (Perugini \& Conner, 2000). Nevertheless, the results indicated that models 1 and 2 did not significantly improve the model fit. Model 3 reanalyzed both linkages of Models 1 and 2 on the validation sample. The rationale for testing this third model was to examine whether results obtained in Models 1 and 2 replicated under cross-validation. The results showed no significant improvement in the fit, $\Delta \chi^{2}{ }_{(5.99)}(\Delta d f=2)=2.8, p>.05$. Even if the beta value of the added path from job autonomy to turnover intention was $\beta=.15$, both the added paths were not significant $(p>.05)$ (see Figure 2). Overall, these results suggested our hypothesized model is the best representation of the data.

Figure 2 reports the standardized coefficients for the relationships among the variables of the Model 3.

Table 2. Comparison of Hypothesized model with Alternative models

\begin{tabular}{lcccccccc}
\hline \multicolumn{1}{c}{ Model } & $\chi^{2}$ & $d f$ & $\Delta \chi^{2}$ & $\Delta d f$ & AIC & CFI & TLI & RMSEA \\
\hline Measurement model & 152.0 & 95 & & & & .97 & .96 & .05 \\
Hypothesized model & 154.3 & 97 & & & 232.34 & .97 & .96 & .05 \\
Alternative model 1 & 153.0 & 96 & $1.3^{*}$ & 1 & 233.01 & .97 & .96 & .05 \\
Alternative model 2 & 152.6 & 96 & $1.7^{*}$ & 1 & 232.56 & .97 & .96 & .05 \\
$\begin{array}{l}\text { Alternative model 3 (on } \\
\text { validation sample) }\end{array}$ & 157.1 & 95 & $2.8^{*}$ & 2 & 239.05 & .97 & .97 & .05 \\
$n=$ & & & & & & & & \\
\hline
\end{tabular}


sample. $n=229$ for Alternative model 3 on validation sample. Alternative model 1 added a path between intrinsic motivation and turnover intention. Alternative model 2 added a path between job autonomy and turnover intention. Alternative model 3 added paths of both Alternative model 1 and Alternative model 2, but it was compared with Hypothesized model on validation sample. $\Delta \chi^{2}=$ difference in $\chi^{2}$ values between models; $\Delta d f=$ difference in degree of freedom values between models; $\mathrm{AIC}=$ Akaike Information Criterion; CFI $=$ Comparative Fit Index; TLI $=$ Tucker-Lewis Index RMSEA $=$ Root-Mean-Square Error of Approximation. ${ }^{*} p>.05$.

Table 3. Common method variance analyses

\begin{tabular}{lccccc}
\hline \multicolumn{1}{c}{ Model } & $\chi^{2}$ & $d f$ & CFI & TLI & RMSEA \\
\hline Training sample & & & & & \\
Trait-only & 152.0 & 95 & .97 & .96 & .05 \\
Method-only & 524.0 & 101 & .78 & .74 & .14 \\
Trait/Method & 100.7 & 79 & .99 & .98 & .04 \\
Trait/Method-R & 103.4 & 88 & .99 & .99 & .03 \\
Validation sample & & & & & \\
Trait-only & 157.1 & 95 & .97 & .97 & .05 \\
Method-only & 672.2 & 101 & .75 & .71 & .16 \\
Trait/Method & 108.8 & 79 & .99 & .98 & .04 \\
Trait/Method-R & 113.9 & 88 & .99 & .98 & .04 \\
\hline
\end{tabular}

$n=213$ for the training sample. $n=229$ for the validation sample.

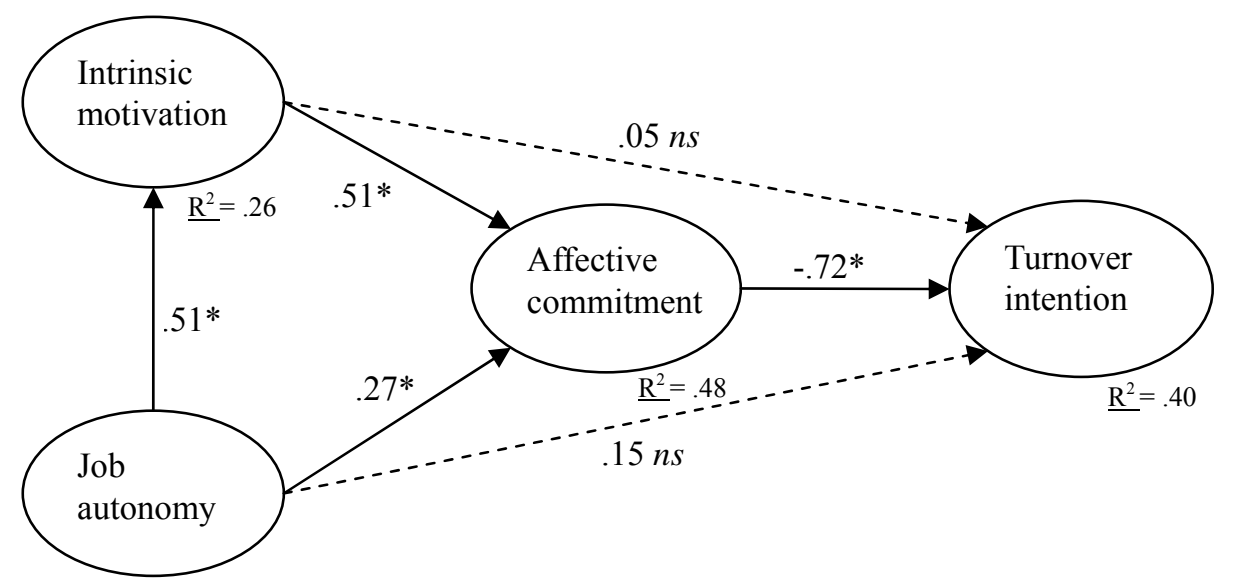

Figure 2. Model 3 with standardized path coefficients on validation sample.

$$
n=229 .{ }^{*} p<.001 \text {. }
$$

\subsection{Tests of Mediation}

In order to test the significance of the mediation effects in SEM, we used the bootstrap method to determine the confidence intervals for mediation effects. We tested indirect effects on the validation sample. Results revealed that affective commitment completely mediates both the relationship of intrinsic motivation and job autonomy to turnover intention. From Table 4 , one can see that the $95 \%$ confidence interval bootstrap estimate for the indirect effect of these variables did not include zero, suggesting a significant total mediation effect. This 
result supported Hypotheses $4 \mathrm{~b}$ and $4 \mathrm{c}$.

Table 4. Mediation model: indirect effects of intrinsic motivation and job autonomy on turnover intention through affective commitment

\begin{tabular}{|c|c|c|c|c|c|c|c|}
\hline \multirow[b]{2}{*}{ Mediator } & \multirow[b]{2}{*}{ Relationship } & \multicolumn{4}{|c|}{ Product of coefficients } & \multicolumn{2}{|c|}{$\begin{array}{c}\text { Bootstrapping } \\
\text { bias-corrected } \\
95 \% \mathrm{CI}\end{array}$} \\
\hline & & Estimate & $S E$ & $Z$ & $p$ & $\begin{array}{c}\text { Lower } \\
\text { limit }\end{array}$ & $\begin{array}{c}\text { Upper } \\
\text { limit }\end{array}$ \\
\hline \multirow{2}{*}{$\begin{array}{l}\text { Affective } \\
\text { commitment }\end{array}$} & IntrMot to TurInt & -.05 & .01 & -4.62 & $<.001$ & -.08 & -.03 \\
\hline & JobAuto to TurInt & -.05 & .01 & -4.79 & $<.001$ & -.07 & -.02 \\
\hline
\end{tabular}

$n=229$. Unstandardized values are presented. Bootstrap sample size $=1000$. Coefficients in boldface denote mediation. $\mathrm{CI}=$ Confidence interval. IntrMot $=$ intrinsic motivation; JobAuto $=$ job autonomy; TurInt $=$ turnover intention .

\section{Discussion}

Driven from Self-Determination theory and from Job Characteristic model, this study provides new insights, in the nursing field, into the relationship among the constructs related to turnover intentions - the latter being historically considered as direct antecedents of the actual turnover (Waters \& Roach, 2006). Previous studies showed that job autonomy is negatively related to turnover intention (Kim \& Stoner, 2008), and it is an important variable for retention strategies (Kramer \& Schmalenberg, 2002). Nevertheless, there are no studies that have used a structural equation modeling to explain how autonomy is related to individual aspects such as work motivation and organizational commitment, and how commitment mediates the relationship between those variables and turnover intention. SDT asserts that autonomy is one of the individual's basic psychological needs which are able to activate self-determined behavior. In this study, we found that job autonomy is positively related to both intrinsic motivation (Gagné \& Deci, 2005; Humphrey et al., 2007) and affective commitment. This result supports findings of Parker et al. (2001) and allows to better understanding how job autonomy is indirectly related to turnover intention. In fact, this research revealed an effect of total mediation by affective commitment on job autonomy-turnover intention relationship, adding an important contribute to the literature. This result highlights that having the opportunity of responsibility and freedom to develop own work activities, can encourage the sense of identification and attachment to work environment that in turn reduce the desire to leave.

Moreover, our research contributes to literature showing the importance of intrinsic motivation to promote affective commitment. This is because of identification and internalization processes, which are considered to be the bases of affective commitment (Meyer \& Allen, 1991). Yet, this study found that affective commitment completely mediates the relationship between intrinsic motivation and turnover intention. This means that employees intrinsically motivated towards their own work, develop a sense of identification and attachment to their organization that in turn is negatively related to turnover intention. This result supports findings of Thatcher et al. (2006). 
Although it is impossible to do causal inferences between variables, this research contributes to identify an important set of variables related to sense of organizational membership, and it highlights the importance of job autonomy as a factor able to strengthen the individual-organization relationship.

Methodologically, this research has contributed to literature in its use of cross-validation technique (Bergman et al., 2002) that has allowed to generalize results obtained on the training sample, validating them on the second random half sample.

\subsection{Limitations}

This study has several limitations that might be addressed in further research. The use of self-report measures without the integration of objective measures, such as absenteeism and real turnover, could raise doubts about the validity of the obtained data (Goffin \& Gellatly, 2001). However, we have ensured that common method variance was not a significant contaminant in this study, but future researches should consider the assessment by supervisors to avoid potential problems related to common method bias.

Yet, although cross-validation technique has shown the generalisability of the model studied on two subsamples, the impossibility to compare measures analyzed with data obtained in different organizational environments and with different types of employees reduces the external validity of the research. To obtain greater support for the model, it might be necessary to replicate the study with different populations of workers.

Moreover, it is important to notice that this study has focused on the intrinsic motivation form and affective commitment dimension, since autonomous motivation can activate involvement and identification with the relevant target (e.g., Lam \& Gurland, 2008), as well as the probability that an individual will become involved in a course of action. Nevertheless, it might be likely that the components of organizational commitment (normative, high sacrifice, and low alternative continuance commitment) play a different role on the association between the other forms of work motivation (identified, introjected and external regulations) and turnover intention.

Finally, another limitation is the lack of experimental and longitudinal design. One should be aware that it is impossible to draw inferences of causality (Mathieu \& Taylor, 2006). Motivation and commitment are two dynamic processes by nature that need longitudinal-type studies to expand the knowledge on these processes and to investigate their evolution across time. Future studies necessarily should consider such a method, and test long-term effects on the relationships examined in the present study and over outcomes such as turnover behavior and absenteeism.

\subsection{Practical Implications, Future Direction and Conclusions}

This research highlights how job autonomy is associated with positive feelings and attitudes at work, and it points out the importance of affective commitment as mediator of relationship between those variables and turnover intention. This means that maintaining the autonomous, motivated and committed workforce it is an important retention's strategy for organizations. 
Thus, this study may help to focus organizational efforts, highlighting the importance of promoting organizational practices oriented to help employees to meet their needs, generating high freedom and responsibility to develop their work. This promotes an "approach motivation" towards targets and feelings of affective affiliation to the organization (Vandenberghe, 2009), all elements that are necessary to success and general organizational efficacy.

We wish to highlight some future guidelines that can further contribute to the understanding of the phenomenon and overcome limitations. First, for the proposed model to guarantee a greater chance of generalizing the results, it would be useful to focus on a different category of workers from different organizations. Moreover, future studies should expand knowledge on these findings examining the role of relational factors such as the bond with supervisor and commitment to supervisor (e.g., Landry, Panaccio, \& Vandenberghe, 2010) to better understand the potential relationship with organizational commitment and turnover intention. In fact, specifically in nursing field, Ribelin (2003) asserted that nurses leave their manager, they do not leave hospitals. This means that relationship with the supervisor might be an important force in nurses' decision to leave, as much as the relationship with the work unit.

In conclusion, we encourage organizations to foster organization-related affective commitment because of its negative association with outcomes such as turnover intention. Results of this study add new knowledge on variables related to retention strategies oriented to increase emotional attachment to an organization and to decrease the likelihood of dysfunctional turnover, by creating work environments that support working practice and actual demands of workers.

\section{References}

Abbasi, S. M., Hollman, K. W., \& Hayes, R. D. (2008). Bad bosses and how not to be one. Information Management Journal, 42, 52-56.

Ajzen, I. (1991). The theory of planned behavior. Organizational Behavior and Human Decision Processes, 50, 179-211.

Akaike, H. (1987). Factor analysis and AIC. Psychometrika, 52, 317-332.

Allen, N. J., \& Meyer, J. P. (1996). Affective, continuance, and normative commitment to the organization: An examination of construct validity. Journal of Vocational Behavior, 49, 252-256.

Anderson, J. C., \& Gerbing, D. W. (1988). Structural equation modeling in practice: a review and recommended two-step approach. Psychological Bulletin, 103, 411-423.

Arbuckle, J. L. (2006). AMOS 7.0 User's Guide. Chicago: SPSS.

Becker, T. E., Billings, R. S., Eveleth, D. M., \& Gilbert, N. W. (1996). Foci and bases of commitment: Implications for performance. Academy of Management Journal, 39, 464-482.

Bergman, M. E., Langhout, R. D., Palmieri, P. A., Cortina, L. M., \& Fitzgerald, L. F. (2002). The (un)reasonableness of reporting: Antecedents and consequences of reporting sexual 
harassment. Journal of Applied Psychology, 87, 230-242.

Bono, J. E., \& Judge, T. A. (2003). Self-concordance at work: understanding the motivational effects of transformational leaders. Academy of Management Journal, 46, 554-571.

Brislin, R. W. (1980). Translation and content analysis of oral and written materials. In H. C. Triandis \& J. W. Berry (Eds.), Handbook of cross-cultural psychology (Vol. 2, pp. 389-444). Boston, MA: Allyn \& Bacon.

Camerino, D., \& Mansano Sarquis, L. M. (2010). Nurses' working conditions, health and well being in Europe (Nurses' Early Exit Study). Professioni Infermieristiche, 63, 53-61.

Camerino, D., Conway, P. M., \& Lusignani, M. (2005). Condizioni di lavoro infermieristico e intenzione di cambiare: risultati dello studio europeo NEXT in Italia. Giornale Italiano di Scienze Infermieristiche, 1, 12-25.

Carmeli, A., \& Gefen, D. (2005). The relationship between work commitment models and employee withdrawal intentions. Journal of Managerial Psychology, 20, 63-86.

Cheung, G. W., \& Lau, R. S. (2008). Testing Mediation and Suppression Effects of Latent Variables. Bootstrapping With Structural Equation Models. Organizational Research Methods, 11, 296-325.

Clugston, M., Howell, J. P., \& Dorfman, P. W. (2000). Does cultural socialization predict multiple bases and foci of commitment? Journal of Management, 26, 5-30.

Deci, E. L. (1980). The psychology of self-determination. Washington, DC: Heath.

Deci, E. L., \& Ryan, R. M. (1985). Intrinsic motivation and self-determination in human behavior. New York, NY Plenum.

Deci, E. L., Connell, J. P., \& Ryan, R. M. (1989). Self-determination in a work organization. Journal of Applied Psychology, 74, 580-590.

Destrebecq, A., Terzoni, S., Colosso, C., Neri, L., \& Brambilla, G. (2009). Intention to leave nursing in a major Milan hospital: current situation and future perspectives. Medicina del Lavoro, 100, 109-119.

Dysvik, A., \& Kuvaas, B. (2010). Exploring the relative and combined influence of mastery-approach goals and work intrinsic motivation on employee turnover intention. Personnel Review, 39, 622-638.

Gaan, N. (2008). Stress, social support, job attitudes and job outcome across Gender. The Icfai University Journal of Organizational Behavior, 52, 34-44.

Gagné, M., \& Deci, E. L. (2005). Self-determination theory and work Motivation. Journal of Organizational Behavior, 26, 331-362.

Gagné, M., Forest, J., Gilbert, M.-H., Aubé, C., Morin, E. M., \& Malorni, A. (2010). The Motivation at Work Scale: Validation evidence in two languages. Educational and Psychological Measurement, 70, 628-646. 
Gautam, T., Dick, R. V., \& Wagner, U. (2001). Organizational commitment in Nepalese setting. Asian Journal of Social Psychology, 4, 239-248.

Goffin, R. D., \& Gellatly, I. R. (2001). A multi-rater assessment of organizational commitment: are self-report measures biased? Journal of Organizational behavior, 22, 437-451.

Griffeth, R. W., Hom, P. W., \& Gaertner, S. (2000). A meta-analysis of antecedents and correlates of employee turnover: update, moderator test, and research implications for the next millennium. Journal of Management, 26, 463-488.

Hackman, J. R., \& Oldham, G. R. (1976). Motivation through the design of work: test of a theory. Organizational Behavior and Human Performance, 16, 250-279.

Hair, J. J. F., Black, W. C., Babin, B. J., Anderson, R.E., \& Tatham, R. L. (2006). Multivariate Data Analysis (6th ed.). Pearson-Prentice Hall, Upper Saddle River: NJ.

Hom, P. W., \& Griffeth, R. (1995). Employee Turnover. South Western Publishing, USA.

Hom, P. W., Griffeth, R. W., \& Sellaro, C. L. (1984). The validity of Mobley's (1977) model of employee turnover. Organizational Behavior and Human Performance, 34, 141-174.

Hu, L. T., \& Bentler, P. M. (1995). Evaluating model fit. In R. H. Hoyle (Ed.), Structural Equation Modeling: concepts, issues, and applications (pp. 76-99). Thousand Oaks, CA: Sage.

Hu, L. T., \& Bentler, P. M. (1999). Cutoff criteria for fit indexes in covariance structure analysis: Conventional criteria versus new alternatives. Structural Equation Modeling, 6, 1-55.

Humphrey, S. E., Nahrgang, J. D., \& Morgeson, F. P. (2007). Integrating motivational, social, and contextual work design features: A meta-analytic summary and theoretical extension of the work design literature. Journal of Applied Psychology, 92, 1332-1356.

Karim, N. H. A. (2010). The impact of work related variables on librarians' organizational commitment and job satisfaction. Malaysian Journal of Library \& Information Science, 15, 149-163.

Kash, B. A., Naufal, G. S., Cortés, L., \& Johnson, C. E. (2010). Exploring factors associated with turnover among registered nurse (RN) supervisors in nursing homes. Journal of Applied Gerontology, 29, 107-127.

Khatri, N., Budhwar, P., \& Fern, C. T. (2001). Explaining Employee turnover in an Asian context. Human Resource Management Journal, 11, 54-74.

Khowaja, K., Merchand, R. J., Hirani, D. (2005). Registered nurses perception of work satisfaction at a Tertiary Care University Hospital. Journal of Nursing Management, 13, 32-39.

Kim, H., \& Stoner, M. (2008). Burnout and turnover intention among social workers: effects 
of role stress, job autonomy and social support. Administration in Social Work, 32, 5-25.

Kramer, M., \& Schmalenberg, C. E. (2002). Magnet hospital staff nurses describe clinical autonomy. Nurses Outlook, 51, 13-19.

Lam, C. F., \& Gurland, S. T. (2008). Self-determined work motivation predicts job outcomes, but what predicts self-determined work motivation? Journal of Research in Personality, 42, 1109-1115.

Landry, G., Panaccio, A., \& Vandenberghe, C. (2010). Dimensionality and Consequences of Employee Commitment to Supervisors: A Two-Study Examination. The Journal of Psychology: Interdisciplinary and Applied, 144, 285-312.

MacKinnon, D. P., Lockwood, C. M., \& Williams, J. (2004). Confidence limits for the indirect effect: Distribution of the product and resampling methods. Multivariate Behavioral Research, 39, 99-128.

Mathieu, J. E., \& Taylor, S. R. (2006). Clarifying conditions and decision points for mediational type inferences in organizational behavior. Journal of Organizational Behavior 27, 1031-1056.

Meyer, J. P., \& Allen, N. J. (1991). A three-component conceptualization of organizational commitment. Human Resource Management Review, 1, 61-89.

Meyer, J. P., \& Allen, N. J. (1997). Commitment in the workplace: theory, research and application. Thousand Oaks, CA: Sage.

Meyer, J. P., \& Herscovitch, L. (2001). Commitment in the workplace: Toward a general model. Human Resource Management Review, 11, 299-326.

Meyer, J. P., Allen, N. J., \& Smith, C. A. (1993). Commitment to the organization and occupations: Extension and test of a three-component conceptualization. Journal of Applied Psychology, 78, 538-551.

Meyer, J. P., Becker, T. E., \& Vandenberghe, C. (2004). Employee commitment and motivation: A conceptual analysis and integrative model. Journal of Applied Psychology, 89, 991-1007.

Miller, Y. (2010). Labour Turnover and its Impact on Customer Service and Success of Restaurants in London. [Online] Available: http://www.articleblast.com (July 6, 2010).

Millette, V., \& Gagné, M. (2008). Designing volunteers' tasks to maximize motivation, satisfaction and performance: the impact of job characteristics on the outcomes of volunteer involvement. Motivation and Emotion, 32, 11-22.

Morgeson, F. P., \& Humphrey S. E. (2006). The work design questionnaire (WDQ): developing and validating a comprehensive measure for assessing job design and the nature of work. Journal of Applied Psychology, 91, 1321-1339.

Mowday, R. T., Steers, R. J., \& Porter, L. W. (1979). The measurement of organizational 
commitment. Journal of Vocational Behavior, 14, 224-247.

Nunnally, J. C. (1978). Psychometric theory (2nd ed.). New York: McGraw-Hill.

Parker, S. K., Wall, T. D., \& Cordery, J. L. (2001). Future work design research and practice: towards an elaborated model of work design. Journal of Occupational and Organizational Psychology, 74, 413-440.

Perugini, M., \& Conner, M. (2000). Predicting and understanding behavioral volitions: The interplay between goals and behaviors. European Journal of Social Psychology, 30, 705-731.

Pierce, J. L., Jussila, I., \& Cummings, A. (2009). Psychological ownership within the job design context: revision of the job characteristics model. Journal of Organizational Behavior, $30,477-496$.

Podsakoff, P. M., MacKenzie, S. B., Lee, J. Y., \& Podsakoff, N. P. (2003). Common method biases in behavioral research: A critical review of the literature and recommended remedies. Journal of Applied Psychology, 88, 879-903.

Preacher, K. J., \& Hayes, A. F. (2008). Asymptotic and resampling strategies for assessing and comparing indirect effects in multiple mediator models. Behavior Research Methods, 40, 879-891.

Ribelin, P. J. (2003). Retention reflects leadership style. Nursing Management, 34, 18-20.

Richardson, H. A., Simmering, M. J., \& Sturman, M. C. (2009). A Tale of Three Perspectives: Examining Post Hoc Statistical Techniques for Detection and Correction of Common Method Variance. Organizational Research Methods 12, 762-800.

Richer, S. F., Blanchard, C., \& Vallerand, R. J. (2002). A motivational model of work turnover. Journal of Applied Social Psychology, 32, 2089-2113.

Shields, M. A., \& Ward, M. (2001). Improving nurse retention in the National Health Service in England: The impact of job satisfaction on intention to quit. Journal of Health Economics, 20, 677-701.

Sjoberg, A., \& Sverke, M. (2000). The interactive effect of job involvement and organizational commitment on job turnover revisited: a note on the mediating role of turnover intention. Scandinavian Journal of Psychology, 41, 247-252.

Tai, T. W. C., Bame, S. I., \& Robinson, C. D. (1998). Review of nursing turnover research, 1977-1996. Social Science and Medicine, 12, 1905-1924.

Takase, M., Yamashita, N., \& Oba, K. (2007). Nurses' leaving intention: antecedents and mediating factors. Journal of Advanced Nursing, 62, 295-306.

Thatcher, J. B., Liu, Y., Stepina, L. P., Goodman, J. M., \& Treadway, D. C. (2006). IT worker turnover: An empirical examination of intrinsic motivation. The Database for Advances in Information Systems, 37, 133-146.

Thompson, C. A, \& Prottas, D. J. (2005). Relationships among Organizational Family 


\section{Macrothink

Support, Job Autonomy, Perceived Control, and Employee well-being. Journal of Occupational Health Psychology, 11, 100-118.

Tuzun, I. K. (2007). Antecedents of Turnover Intention toward a Service Provider. The Business Review, 8, 128-135.

Vandenberghe, C. (2009). Organizational Commitments. In H. J. Klein, T. E. Becker, \& J. P. Meyer, (Eds.), Commitment in organizations: Accumulated wisdom and new directions (pp. 99-135). New York: Routledge/Taylor and Francis.

Wagner, C. M. (2010). Predicting nursing turnover with catastrophe theory. Journal of Advanced Nursing, 66, 2071-2084.

Waters, L. K., \& Roach, D. (2006). Job satisfaction, behavioral intention, and absenteeism as predictors of turnover. Personnel Psychology, 32, 393-397.

\section{Copyright Disclaimer}

Copyright reserved by the author(s).

This article is an open-access article distributed under the terms and conditions of the Creative Commons Attribution license (http://creativecommons.org/licenses/by/3.0/). 